\title{
Maternal and neonatal outcome in cases of premature rupture of membranes beyond 34 weeks of gestation
}

\author{
Sanjay Kumar Sharma ${ }^{1}$, Madhusudan Dey ${ }^{2 *}$
}

\author{
${ }^{1}$ Department of Obstetrics and Gynecology, Military Hospital, Amritsar, Punjab, India \\ ${ }^{2}$ Department of Obstetrics and Gynecology, Armed Forces Medical College, Pune, Maharashtra, India
}

Received: 11 January 2017

Revised: 10 February 2017

Accepted: 03 March 2017

\section{*Correspondence:}

Dr. Madhusudan Dey,

E-mail: deym1@yahoo.com

Copyright: (C) the author(s), publisher and licensee Medip Academy. This is an open-access article distributed under the terms of the Creative Commons Attribution Non-Commercial License, which permits unrestricted non-commercial use, distribution, and reproduction in any medium, provided the original work is properly cited.

\section{ABSTRACT}

Background: Preterm premature rupture of membrane (PPROM) and premature rupture of membrane (PROM) are associated with various maternal and neonatal complications. Management guidelines regarding rupture of membrane before labour is still controversial. The study was carried out to determine the various maternal and neonatal outcomes associated with rupture of membranes beyond 34 weeks of gestation.

Methods: It was a prospective observational study carried out in a tertiary care teaching hospital for a period of one year. All the pregnant women with rupture of membrane beyond 34 weeks are included in the study. After establishment of diagnosis of rupture of membranes, antibiotics were started and all of them were induced after 6 hours if they did not have spontaneous labour. Various maternal and neonatal outcomes were noted and statistical analysis carried out.

Results: Incidence of rupture of membrane in our study was $4.2 \% .92 \%$ of patients delivered within 24 hours of rupture of membrane and $18 \%$ of them required caesarean section. 5 neonates had respiratory distress syndrome and 1 neonate had sepsis.

Conclusions: Induction of labour and delivery within 24 hours of rupture of membranes associated with low incidence of maternal and neonatal adverse outcome.

Keywords: Induced, Neonatal, Premature, Rupture of membrane, Sepsis

\section{INTRODUCTION}

Premature rupture of membranes (PROM) is defined as rupture of membranes before onset of labour. It continues to be obstetric enigma in terms of cause and management despite advanced perinatal care. PROM and preterm premature rupture of membranes (PPROM) i.e. rupture before 37 completed weeks, has long been associated with high perinatal as well as maternal morbidity. ${ }^{1}$ A prolonged PROM is the rupture of membranes that persists for more than 24 hours prior to the onset of labour. The interval between rupture of membranes and onset of labour is called latent period of leaking, which is the key factor for determining maternal and fetal outcome.

Foetal membranes insulate foetus and amniotic fluid from microbial infections. Some of serious complications associated with PROM include chorioamnionitis, cord prolapse, placental abruption, preterm labour leading to various foetal complications like foetal death, neonatal pulmonary hypoplasia, and respiratory distress syndrome (RDS), neonatal sepsis, intraventricular haemorrhage. ${ }^{2}$ The frequency and severity of complications is inversely proportional to the gestational age at the time of membrane rupture and its duration. 
The management of PROM has long been in controversy in the practice of obstetrics. The advocates of aggressive termination of pregnancy have placed major emphasis on the threat of potentially severe maternal and foetal infection. Some advocate conservative management of PROM in absence of labour or signs of infection to allow for a favourable gestational age.

The aetiology of spontaneous PROM is not known exactly but it has been speculated that infection or degeneration may weaken the membranes and spontaneous rupture. The membranes respond to various stimuli like membrane stretching, infections of reproductive tract by producing mediators like prostaglandins (PGs), cytokines and other enzymes.

PPROM remains a major cause of preterm delivery, neonatal morbidity and mortality. The underlying multifactorial etiology and the lack of differentiation of preterm labour with intact membranes and that following PPROM in research studies has made preventive strategies difficult to develop. Treatment strategies including antibiotic therapy and the use of corticosteroids in women who have already undergone PPROM have improved neonatal outcomes significantly. However the prediction and prevention of PPROM remains a significant challenge in obstetrics.

This study has been carried out to determine the various maternal and neonatal outcomes in cases of premature rupture of membranes beyond 34 weeks period of gestation. For our study PROM combines rupture of membrane starting from 34 weeks till term.

\section{METHODS}

This was a prospective observational study carried out at a tertiary care teaching hospital from Dec 2012 to Nov 2013. Permissions from Institutional Ethical Committee were obtained. An informed consent was obtained from all the participants enrolled in the study. All pregnant ladies presenting to hospital labour room with history of rupture of membrane beyond 34 weeks period of gestation were included in the study. Rupture of membrane was established by clinical examination and Nitrazine test in the labour room. Multiple pregnancy and patients who were in active labour were excluded from the study. Period of gestation was established from the last menstrual period and in cases of unsure dates, first trimester ultrasonographic date was taken into consideration.

After doing general examination of patient, speculum examination was done and vaginal swab was taken. Blood counts were sent. Per vaginal examination was done using sterile precautions if required. Fetal wellbeing was established by admission test. Antibiotics were started to the patient as per hospital policy i.e. Inj Ampicillin $1 \mathrm{gm} \mathrm{IV} 6$ hrly after antibiotic sensitivity test and Tab Azithromycin $500 \mathrm{mg}$ OD. Antibiotics were given for a maximum period of 5 days. In all cases antibiotic was started but surfactant was not given as per institutional policy. Fetal wellbeing and liquor state was established by doing admission test and AFI. Patients who were in labour with cephalic presentation were allowed to progress spontaneously and those not in labour were observed for $6 \mathrm{hrs}$ for onset of spontaneous labour. If patient has not gone into labour for $6 \mathrm{hrs}$ were induced depending upon cervical condition with cerviprime or oxytocin infusion.

Those with malpresentations were taken up for scheduled LSCS. Those who were given trial of vaginal delivery were taken up for operative or instrumental deliveries for Obstetric indication. Neonates with birth weight more than $2 \mathrm{~kg}$ and normal APGAR score were observed in labour room for $4 \mathrm{hrs}$, breast feeding was established in labour room. If postnatal course was uneventful both neonate and mother were shifted to the ward however blood sugar of neonate was monitored at 2, 4, 8, 16, and $24 \mathrm{~h}$ after delivery. Neonates were observed in the ward for $48 \mathrm{hrs}$ and if neonatal course was uneventful and maternal condition was stable they were discharged with post natal advice.

\section{Data analysis}

Details of all cases of PROM were noted in performa and data was entered in the excel sheet. Quantitative analysis was done using frequency using Epi info software.

\section{RESULTS}

Total no of deliveries during the period of study were 2336. 109 pregnant women reported to labour room with history of leaking. On examination, leaking was not demonstrable in 11 patients and 12 patients were found to be in labour. Among the 86 remaining patients, 14 of them were below 34 weeks period of gestation and they were excluded from the study. The incidence of PROM in this study was $4.2 \%$.

Table 1: Socio-demographic factors of PROM.

\begin{tabular}{|lll|}
\hline (n=76) Maternal age (yrs) & No(n) & Percentage \\
\hline$<22$ & 24 & 33.3 \\
\hline $23-27$ & 38 & 52.7 \\
\hline$>28$ & 10 & 13.8 \\
\hline Parity & & \\
\hline Primipara & 45 & 62.5 \\
\hline Multipara & 27 & 37.5 \\
\hline Socioeconomic status & & \\
\hline Low & 27 & 37.5 \\
\hline Middle & 41 & 56.9 \\
\hline High & 4 & 5.6 \\
\hline H/o abortion & & \\
\hline No & 56 & 77.7 \\
\hline Yes & 16 & 22.3 \\
\hline
\end{tabular}


Table 1 shows the socio-economic factors associated in this study and it shows that most of the pregnant women who had PROM were between 22-27 years of age. Incidence of PROM was more in primipara.

Table 2: Obstetrics factors for PROM.

\begin{tabular}{|c|c|c|}
\hline Obstetric factors $(n=72)$ & No (n) & Percentage \\
\hline \multicolumn{3}{|c|}{ Leaking to delivery interval } \\
\hline$<12 \mathrm{H}$ & 39 & 54.2 \\
\hline $13-24 \mathrm{H}$ & 27 & 37.5 \\
\hline $25-96 \mathrm{H}$ & 06 & 8.3 \\
\hline \multicolumn{3}{|l|}{ POG at delivery } \\
\hline 34-37 weeks & 23 & 31.9 \\
\hline$>37$ weeks & 49 & 68.1 \\
\hline \multicolumn{3}{|l|}{ Mode of delivery } \\
\hline Vaginal & 57 & 79.1 \\
\hline Instrumental & 02 & 2.7 \\
\hline Caesarean section & 13 & 18.1 \\
\hline
\end{tabular}

Among the PROM cases, $68 \%$ cases occurred at term as shown in table 2. Almost 92\% of PROM patients delivered within 24 hours and $79 \%$ of them had normal vaginal delivery and $18 \%$ of them required caesarean section.

Table 3: Neonatal outcome of PROM.

\begin{tabular}{|lll|}
\hline Neonatal factors $(\mathbf{n = 7 2})$ & No $(\mathbf{n})$ & Percentage \\
\hline NICU admissions & 11 & 15.3 \\
\hline Support in NICU & & \\
\hline Observation & 05 & 6.9 \\
\hline O2 by hood & 02 & 2.7 \\
\hline CPAP & 02 & 2.7 \\
\hline Ventilator & 02 & 2.7 \\
\hline Birth weight $(\mathbf{K g})$ & & \\
\hline$<1.5$ & 0 & - \\
\hline $1.5-1.99$ & 2 & 2.7 \\
\hline $2-2.5$ & 23 & 32 \\
\hline$>2.5$ & 47 & 65.3 \\
\hline Length of stay at hospital & \\
\hline Upto 2 days & 45 & 62.5 \\
\hline $2-4$ days & 19 & 26.3 \\
\hline$>4$ days & 8 & 11.2 \\
\hline Morbidities & \\
\hline Jaundice & 5 & 6.9 \\
\hline RDS & 5 & 6.9 \\
\hline Sepsis & 1 & 1.3 \\
\hline Superficial infection & 5 & 6.9 \\
\hline
\end{tabular}

Neonatal outcomes were shown in table 3. Total 11 neonates required NICU admissions and 2 of them required ventilator support. $89 \%$ of the neonates discharged within 4 days. $35 \%$ of the babies had birthweight below $2.5 \mathrm{Kg}$. 5 babies was diagnosed as a case of respiratory distress syndrome (RDS) and 1 neonate had sepsis.
Table 4: Organisms grown in vaginal swab.

\begin{tabular}{|lll|}
\hline Name of the organism & No $(\mathbf{n})$ & Percentage \\
\hline Gr B streptococcus & 2 & 16.6 \\
\hline E Coli & 10 & 83.4 \\
\hline
\end{tabular}

E Coli was the predominant organism grown in vaginal swab and Gr B streptococcus was grown in 2 cases as shown in Table 4.

\section{DISCUSSION}

The incidence of preterm premature rupture of membranes (PPROM) is about 3-8\% and premature rupture of membranes at term i.e. beyond 37 weeks period of gestation also complicates approximately $8 \%$ of pregnancies. ${ }^{3}$ In our study, the incidence of premature rupture of membrane beyond 34 weeks period of gestation was $4.2 \%$. With advancing maternal age the incidence of PROM also increases but in our study $86 \%$ women who had PROM were below 28 years of age. ${ }^{3}$ This may be due to most of the deliveries occurring to women below 30 years of age. $62.5 \%$ primigravidas had PROM as compare to $37.5 \%$ multigravida in this present study. $77 \%$ of pregnant women who had PROM had no prior history of abortion.

According to Hannah, Peleg and their associates, in their large RCT of 5042 pregnancies with ruptured membranes concluded that labour induction with oxytocin was the preferred management in PROM at term. ${ }^{4,5}$ Labour induction group had significantly lower intrapartum and postpartum infections. There was increased incidence of adverse pregnancy outcome in cases of term PROM cases when managed expectantly at home as compared to in hospital care. ${ }^{4}$ In our study, all the pregnant women with PROM beyond 34 weeks period of gestation were induced either by oxytocin or dinoprostone gel depending on the cervical favourability. Almost $92 \%$ of the pregnant women were delivered within 24 hours of rupture of membranes. $18 \%$ of pregnant women with PROM underwent caesarean section in this study as compared to $26.5 \%$ caesarean section rate for all pregnancies during the study period.

Use of prophylactic antibiotics are recommended in PPROM but benefit of prophylactic antibiotics in women with ruptured membranes at term before labour is unclear according to Passos et al. ${ }^{6}$ We have used antibiotics in all cases of PROM in this study. Infection rate of 13.9 percent was noted in the mothers both intrapartum and postpartum according to Okeke et al. ${ }^{3}$ In our study only one case had superficial wound infection after caesarean section. The low incidence of infection may be because of antibiotic use and most of the deliveries completed within 24 hours of rupture of membrane as most of the studies shows that if the latency period increased beyond 24 hours after rupture of membranes, there is increased incidence of infection related morbidity. Out of 12 cases where vaginal swab culture grown organism, $83 \%$ of 
them were E. Coli and only 2 of them were sensitive to ampicillin. As the gestation increases, incidence of fetal morbidity and mortality decreases. The main reason for neonatal morbidity and mortality in cases of PROM is infection. The incidence of perinatal mortality was $5 \%$ with most common causes being neonatal sepsis and pneumonia and the author concluded that the lesser the time interval between the rupture of menbranes and delivery, the lesser was the maternal and perinatal morbidity and mortality. ${ }^{7}$ In our study, there was no case of perinatal mortality. Among the $15 \%$ neonates required NICU admission, 5\% of them required continuous positive airway pressure (CPAP) or ventilator support. One neonate had sepsis among the various neonatal morbidities as shown in Table 1 . The neonate was treated with antibiotics for 7 days and roomed in with mother. Mozurkewich and associates reported lower incidences of chorioamnionitis, metritis, and NICU admissions for women with term ruptured of membranes whose labour was induced compared to those managed conservatively. These results were in accordance with our study. ${ }^{8}$

Prospective design and inclusion of all pregnant women with rupture of membrane beyond 34 weeks of gestation for a period of one year were strength of our study. Single centre study with no comparative arm was limitation of the study.

\section{CONCLUSION}

Induction of labour and delivery within 24 hours of rupture of membranes associated with low incidence of maternal and neonatal adverse outcome.

\section{Funding: No funding sources}

Conflict of interest: None declared

Ethical approval: The study was approved by the Institutional Ethics Committee

\section{REFERENCES}

1. El-Messidi A, Cameron A. Diagnosis of premature rupture of membranes: inspiration from the past and insights for the future. J Obstet Gynaecol Canada. 2010;32(6):561-9.

2. Medina TM, Hill DA. Preterm Premature Rupture of Membranes: Diagnosis and management. Am Fam Physician. 2006;73:659-64.

3. Okeke TC, Enwereji JO, Okoro OS, Adiri CO, Ezugwu EC, Agu PU. The incidence and management outcome of preterm premature rupture of membranes (pprom) in a tertiary hospital in Nigeria. Am J Clini Med Res. 2014;2(1):14-7.

4. Cunningham FG, Lenevo KJ, Bloom SL. Abnormal labour, Chapter 23. William's Obstetrics, 24th ed. 2014;462.

5. Datta MR, Kabiraj M. Induction of labour with oral misoprostol in women with prelabour rupture of membranes at term. JOGI. 2007;57(6):505-8.

6. Passos F, Cardose K, Coelho AM. Antibiotic prophylaxis in premature rupture of membranes at term. Obstet Gynecol. 2012;120:1045.

7. Revathi V, Sowjanya R, Lavanya S. Maternal and Perinatal Outcome in Premature Rupture of Membranes at Term. IOSR J Dent Medic Sci. 2015;14(4):12-5.

8. Mozurkewich E, Chilimigras J, Koepke E. Indications for induction of labour: a best-evidence review. BJOG. 2009;116(5):626.

Cite this article as: Sharma SK, Dey M. Maternal and neonatal outcome in cases of premature rupture of membranes beyond 34 weeks of gestation. Int $\mathbf{J}$ Reprod Contracept Obstet Gynecol 2017;6:1302-5. 